\title{
A CONJECTURE ABOUT THE INERTIA OF HERMITIAN MATRICES
}

\author{
C. M. DA FONSECA
}

Abstract. Let $H$ be a Hermitian matrix which has been decomposed into $m$ rows and $m$ columns of blocks. Suppose further that we know the inertia of each diagonal block and a range of possible ranks for each off-diagonal block. What are the possible inertias of $H$ ?

In this paper, a conjecture on the inertias of Hermitian matrices with a prescribed $3 \times 3$ block decomposition is presented, based on several important works on the subject.

Mathematics subject classification (2000): 15A57, 15A42.

Key words and phrases: tridiagonal block matrices, Hermitian matrices, inertia.

\section{REFERENCES}

[1] BRYAN E. CAIN, The inertia of a Hermitian matrix having prescribed diagonal blocks, Linear Algebra Appl., 37 (1981), 173-180.

[2] BRYAN E. CAIN, E. MARQUES DE SÁ, The inertia of a Hermitian matrix having prescribed complementary principal submatrices, Linear Algebra Appl., 37 (1981), 161-171.

[3] BRyAN E. CAIN, E. MARQUES DE SÁ, The inertia of Hermitian matrices with a prescribed $2 \times 2$ block decomposition, Linear and Multilinear Algebra, 31 (1992), 119-130.

[4] BRyAn E. CAIN, E. MARQUES DE SÁ, The inertia of certain skew-triangular block matrices, Linear Algebra Appl., 160 (1992), 75-85.

[5] DAVID CARLSON, HANS SCHNEIDER, Inertia theorems for matrices: the semidefinite case, J. Math. Anal. Appl., 6 (1963), 430-446.

[6] NIR COHEN, JEROME DANCIS, Inertias of block band matrix completions, SIAM J. Matrix Anal. Appl., 19 (1998), 583-612.

[7] JEROME DANCIS, The possible inertias for a Hermitian matrix and its principal submatrices, Linear Algebra Appl., 85 (1987), 121-151.

[8] JEROME DANCIS, Several consequences of an inertia theorem, Linear Algebra Appl., 136 (1990), $43-61$.

[9] JEROME DANCIS, Ranks and inertias of Hermitian block Toeplitz matrices, Linear Algebra Appl., 353 (2002), 21-32.

[10] C. M. DA FONSECA, The inertia of certain Hermitian block matrices, Linear Algebra Appl., 274 (1998), $193-210$

[11] C. M. DA FONSECA, The inertia of Hermitian block matrices with zero main diagonal, Linear Algebra Appl., 311 (2000), 153-160.

[12] R. Freund, T. HuCKLE, On H-contractions and the extension problem for Hermitian block Toeplitz. matrices, Linear and Multilinear Algebra, 25 (1989), 27-37.

[13] Frank H. Hall, ZhongShan LI, Di WANG, Symmetric sign pattern matrices that require unique inertia, Linear Algebra Appl., 338 (2001), 153-169.

[14] EMILIE V. HAYNSWORTH, Determination of the inertia of some partitioned Hermitian matrices, Linear Algebra Appl., 1 (1968), 73-81.

[15] EmiliE V. HAYNSWORTH AND A. M. OSTROWSKI, On the inertia of some classes of partitioned matrices, Linear Algebra Appl., 1 (1968), 299-316.

[16] AlEXANDER OSTROWSKI, HANS SCHNEIDER, Some theorems on the inertia of general matrices, J. Math. Anal. Appl., 4 (1962), 72-84.

[17] S. PERLIS, Theory of Matrices, Addison-Wesley, MA (1952). 
[18] E. MARQUES DE SÁ, On the inertia of sums of Hermitian matrices, Linear Algebra Appl., 37 (1981), $143-159$.

[19] Robert C. ThOMPSOn, Linda J. FreEde, The eigenvalues of sums of Hermitian matrices, Linear Algebra Appl., 4 (1971), 369-376. 